\section{Bond Energies of Some Alkali Fluorides}

THE attenuation of microwaves by flames containing traces of alkali metals may be used to determine the electron concentration, arising from the ionization of the alkali, in these flames ${ }^{1,2}$. If a halogen is added to such a flame, the electron concentration is reduced directly by the formation of negative ions, and indirectly by the formation of the alkali halide ${ }^{3,4}$. Flame photometric studies show that the halogens also reduce the excess hydrogen atom concentration in the flame ${ }^{5}$; but it has been observed that fluorine has the least effect ${ }^{8}$. This reduetion makes it difficult to estimate the bond energies of the alkali halides from microwave studies?, because of the indirect nature of the arguments used in the estimations. In the case of fluorine, however, the argument is simplified by the unimportance of the negative ion effect, since the electron affinity of fluorine is low relative to the bond energies of the alkali fluorides, and by the much smaller disturbance produced in the hydrogen atom concentration. In addition, the observations are made at high temperatures where the hydrogen atom coneentration approaches equilibrium ${ }^{5}$ and it is possible to obtain reliable and consistent results, which it is of interest to place on record.

Sodium fluoride has been examined over the temperature-range $2,300-2,600^{\circ} \mathrm{K}$., using perfluoromethylcyclohexane as source of fluorine, and the dissociation constant determined, assuming the dissociation energy of hydrogen fluoride ${ }^{9}$ to be 134 kcal. A graphical determination of the dissociation energy (Fig. 1) gives a value of 124 kcal., equivalent to $119 \mathrm{kcal}$. at $0^{\circ} \mathrm{K}$., in agreement with a statistical 'Third law' value of $120 \mathrm{kcal}$, calculated from the measurement at $2,400^{\circ} \mathrm{K}$. It is also possible to estimate the difference between the bond energies of hydrogen fluoride and sodium fluoride directly from the experimental results. This difference is 14 kcal., which indicates that the bond energy of sodium fluoride is $120 \mathrm{kcal}$. This concordance shows that the disturbing effects described above are, indeed, negligible. Potassium fluoride could not

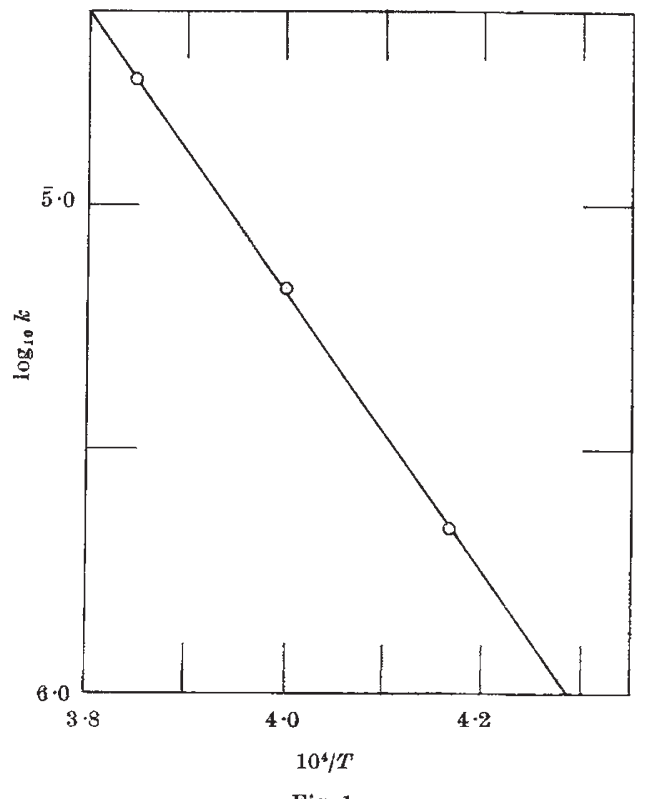

Fig. 1 conveniently be examined over this temperaturerange; but a statistical calculation at $2,400^{\circ} \mathrm{K}$. gave the bond energy as $117 \mathrm{keal}$. Lithium fluoride could only be examined at the highest temperature $\left(2,600^{\circ}\right.$ $\mathrm{K}$.) and a statistical calculation put the bond energy at $141 \mathrm{kcal}$. These values are in good agreement with the thermodynamic predictions of Smith and Sugden ${ }^{10}$ but differ somewhat from other authorities ${ }^{11,12}$. They are, however, in good agreement with some values determined by flame photometry in these laboratories recently ${ }^{13}$.

Thanks are due to Imperial Chemical Industries, Ltd., General Chemicals Division, for the gift of chemicals.

\section{F. M. PAGE \\ T. M. SUGDEN}

Department of Physical Chemistry, University of Cambridge. April 22.

${ }^{1}$ Pelcher and Sugden, Proc. Roy. Soc., A, 201, 480; 202, 17 (1950). ${ }^{2}$ Smith and Sugden, Proc. Roy. Soc., A, 211, 31, 52 (1952).

${ }^{3}$ Page, Disc. Farad. Soc., 19, 87 (1955).

4 Sugden, Disc. Farad. Soc., 19, 68 (1955).

5 Bulewicz, James and Sugden, Proc. Roy. Soc., A, 227, 312 (1958). - Bulewicz and Page (unpublished work).

Page, thesis (Cambridge, 1955).

${ }^{8}$ Page and Sugden (to be published). "Cottrell, "The Strengths of Chemical Bonds" (Butterworths, Lon-

${ }^{10}$ Smith and Sugden, Proc. Roy. Soc., A. 219, 204 (1953).

1 Gaydon, "Dissociation Energies-Spectra of Diatomic Molecules" (London, 1957)

${ }^{12}$ Barrow and Caunt, Proc. Roy. Soc., A, 219, 120 (1953)

ss Bulewicz and Sugden (to be published).

\section{Tetrahedral Co-ordination in $\mathrm{Ni}$ (II)}

LINGATELTER ${ }^{1}$ has suggested that the occurrence of blue-coloured Ni en ${ }_{2}(\mathrm{NCS})_{2}$ and $\mathrm{Ni}$ en $\left(\mathrm{H}_{2} \mathrm{O}\right)_{4}\left(\mathrm{NO}_{3}\right)_{2}$ for which $\mathrm{X}$-ray evidence gives 6 co-ordination for the nickel atom contradicts the criteria for identifying tetrahedrally co-ordinated $\mathrm{Ni}(\mathrm{II})$ suggested in my earlier communication of the same title ${ }^{2}$, with the implication that these criteria are invalid.

The basic criterion laid down ${ }^{2}$ was the disappearance of the characteristic peak in the region of $400 \mathrm{~m} \mu$ of octahedrally co-ordinated $\mathrm{Ni}(\mathrm{II})$, which usually has a green colour. With the disappearance of this peak, a deep blue colour would be expected to result, other things being equal. A property which would suggest the possibility of a tetrahedral 4 co-ordinate condition would therefore be possession of a blue colour. However, since a shift of the $400-\mathrm{m} \mu$ peak to slightly lower wave-lengths could give the same effect so far as the eye alone is concerned, verification by spectral analysis would be an obvious require. ment.

Ballhausen ${ }^{3}$ has used the absorption spectra of the various stages of complexing of $\mathrm{Ni}(\mathrm{II})$ with ethylene diamine to show the spectra of $\left[\mathrm{Ni} \text { en }\left(\mathrm{H}_{2} \mathrm{O}\right)_{4}\right]_{+}^{+}$and $\left[\mathrm{Ni} \text { en }{ }_{2}\left(\mathrm{H}_{2} \mathrm{O}\right)_{2}\right]^{++}$, and in fact the $400 \mathrm{mu}$ peak (as well as the others) has been shifted towards lower wave-lengths, but increased, not diminished, in intensity. Dr. R. G. Wilkins, of the University of Sheffield, has kindly shown me a solid preparation of the salt, $\left[\mathrm{Ni}\right.$ en $\left.\left(\mathrm{H}_{2} \mathrm{O}\right)_{4}\right]\left(\mathrm{NO}_{3}\right)_{2}$, which is light blue, and the absorption spectra he has obtained for icecold aqueous solutions of the salt correspond closely to that given by Ballhausen ${ }^{3}$. This blue-coloured complex cation therefore meets the criteria for 6 co-ordination of $\mathrm{Ni}(\mathrm{II})$, and it is no surprise that $\mathrm{X}$-ray investigation of the related salts verifies this. 